\title{
Development and validation of college students' tuberculosis knowledge, attitudes and practices questionnaire (CS-TBKAPQ)
}

Hualin Jiang ${ }^{1}$, Shaoru Zhang ${ }^{1 *}$, Yi Ding ${ }^{2}$, Yuelu Li ${ }^{1}$, Tianhua Zhang ${ }^{3}$, Weiping Liư ${ }^{3}$, Yahui Fan ${ }^{1}$, Yan Li ${ }^{1}$, Rongqiang Zhang ${ }^{4}$ and Xuexue $\mathrm{Ma}^{1}$

\begin{abstract}
Background: China faces many challenges in controlling tuberculosis (TB). One significant challenge is the control of college students' TB. In particular, cross-sectional studies of college students' knowledge, attitudes and practices (KAP) in regard to TB have attracted substantial attention. However, few measurement tools have been developed to aid processes related to expert consultation, pre-testing, reliability and validity testing. Our study developed the College Students' TB Knowledge Attitudes and Practices Questionnaire (CS-TBKAPQ) following the scale development steps.

Methods: The construction of the CS-TBKAPQ was based on the Theory of Knowledge, Attitude, Belief, and Practice (KABP or KAP). The item pool was compiled from literature reviews and individual interviews. The reliability validation was assessed by calculating Cronbach's a coefficient, the split-half reliability coefficient, and the test-retest reliability coefficient. Construct validity was assessed using exploratory factor analysis (EFA) and confirmatory factor analysis (CFA). The diagnostic accuracy was evaluated using the World Health Organization Advocacy, Communication and Social Mobilization KAP Survey Questionnaire (WHO-TBKAPQ) as the reference standard.

Results: A total of 31 questionnaire items were proposed. Cronbach's a coefficient, the split-half reliability coefficient and the test-retest reliability coefficient were $0.86,0.78$ and 0.91 . Four factors that explained $62.52 \%$ of the total variance were also identified in EFA and confirmed in CFA. The CFA model fit indices were $x^{2} / d f=1.82(p<0.001), \mathrm{GFI}=0.925$, $\mathrm{AGFI}=0.900, \mathrm{RMR}=0.068$, and RMSEA $=0.049$. The CS-TBKAPQ was significantly correlated with the WHO-TBKAPQ and the Chinese Public TB KAP Questionnaire (CDC-TBKAPQ) developed by the Chinese Center for Disease Control and Prevention $(r=0.59,0.60, p<0.001)$. The receiver operating characteristics curve (ROC) analysis suggested a cut-off point of 47.5 , with which the CS-TBKAPQ showed a sensitivity of $73.63 \%$ and a specificity of $80.51 \%$ in identifying students with low-level KAP. The positive and negative predictive values were $83.23 \%$ and $69.91 \%$.

Conclusions: The findings of this study demonstrate that the CS-TBKAPQ is a reliable and valid tool for measuring the KAP towards TB in college students.
\end{abstract}

Keywords: Tuberculosis, College students, Knowledge, Attitudes and practices, Reliability, Validity, Diagnostic accuracy

\footnotetext{
* Correspondence: tgshru011@126.com

${ }^{1}$ Health Science Center, Xi'an Jiaotong University, Xi'an city, China

Full list of author information is available at the end of the article
}

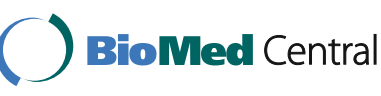

(c) The Author(s). 2017 Open Access This article is distributed under the terms of the Creative Commons Attribution 4.0 International License (http://creativecommons.org/licenses/by/4.0/), which permits unrestricted use, distribution, and reproduction in any medium, provided you give appropriate credit to the original author(s) and the source, provide a link to the Creative Commons license, and indicate if changes were made. The Creative Commons Public Domain Dedication waiver (http://creativecommons.org/publicdomain/zero/1.0/) applies to the data made available in this article, unless otherwise stated. 


\section{Background}

Tuberculosis (TB) remains a major global health problem, especially in the Southeast Asia and Western Pacific regions [1]. China ranks third among the 22 highburden countries and faces challenges in protecting high-risk, vulnerable and special populations from TB [1]. College students have become a high-risk group for TB [2]. Severe endocrine system fluctuations [3], high population density, close contact, and greater mobility in vocations are contributing factors towards TB infection and transmission in college students. According to the China Diseases Monitoring Information Report Management System, 37,040 students suffered from TB in 2013, which represents $4.10 \%$ of the country's total TB patients. Among all students infected with TB, 85\% were between 15 and 24 years old.

Interest in TB KAP research among college students has recently grown, especially using cross-sectional studies. TB is often neglected due to its atypical early symptoms [4]. Poor knowledge and attitudes cause delays in seeking cures and reporting to the medical staffs at schools, leading to a high prevalence of TB in colleges [5]. Limited physical exercise, poor nutrition and irregular routines aggravate TB infection [6].

The most common approach in KAP assessment is the questionnaire. There are several useful tools for measuring the KAP towards TB in cross-sectional surveys. Scholars have developed items through expert consultation [7]. They have also evaluated clarity and intelligibility by pre-testing [8, 9] and have tested internal consistency reliability [10]. However, a questionnaire based on the scale development steps has not yet been reported. There is no specific research on questionnaire development relevant to TB KAP for college students. The World Health Organization (WHO) published the Advocacy, Communication and Social Mobilization TB KAP Survey Questionnaire (WHO-TBKAPQ) [11]. The Public TB KAP Questionnaire (CDC-TBKAPQ), a widely used tool in China, was developed by the Chinese Center for Disease Control and Prevention (CDC) in 2006. These two generic questionnaires are widely used in public KAP surveys and focus on general knowledge, attitudes towards TB patients and health education, as well as the practices of initiative learning and knowledge dissemination. College campuses are high-density locations that create favourable conditions for TB transmission [12]. The crowded situation in both classrooms and dormitories increases the risk of transmission or an epidemic outbreak. Seeking medical services in a timely manner after disease onset, reporting the disease to the school staff, coordination of disease screening and preventive treatment will be a focus of the questionnaire [8]. Accordingly, it is important to develop a KAP questionnaire specifically for college students.
Based on "Advocacy, Communication and Social Mobilization for TB control-A Guide to Developing KAP Surveys" published by WHO [11], we developed the college students' TB KAP questionnaire (CS-TBKAPQ) by following the steps of literature review, expert consultation, and pre-testing. We then assessed the reliability, validity, and diagnostic accuracy of the CS-TBKAPQ using factor analysis, correlation analysis, and diagnostic testing.

\section{Methods \\ Participants \\ Participants and setting}

Participants were recruited from universities in Xi'an city of Shaanxi Province between March and June of 2016. The inclusion criteria were (1) college students, (2) nonmedicine majors, (3) healthy without TB, and (4) never suffered from TB.

\section{Sample size}

\section{Requirement of diagnostic test on sample size}

The following is the formula to determine the sample size needed to employ a diagnostic test: $n=\left(\frac{z_{\alpha}}{\delta}\right)^{2}(1-p) p$.

Based on the assumption that $p=0.75$ (representing sensitivity or specificity), $\delta=0.08$ (representing permitted minimum error), $\alpha=0.05$ (representing I type error, $z=1.96$ accordingly), and a $10 \%$ non-respondent rate in our estimate, a total sample size of 249 was necessary.

\section{Requirement for a factor analysis of the sample size}

The minimum sample size recommended is five participants per item. As the number of the items was intended to be 30, a minimum of 150 participants were needed [13]. The EFA sample and the CFA sample should be two independent samples, the sizes of which should not be fewer than 200 [14] and 300 participants, respectively. Given a $10 \%$ non-response rate, a total sample of 550 participants was needed. According to the requirements of both the diagnostic test and the factor analysis, the minimum sample size was set at 550 participants.

\section{Sample technique}

Simple random sampling was adopted, in which six of the 63 universities in Xi'an city of Shaanxi Province were selected using a table of random numbers. Then, 100 college students were selected according to student ID number using a systematic sampling technique from each of the selected universities.

\section{Procedure}

Phase 1: Framework for the development of the CS-TBKAPQ The CS-TBKAPQ was developed with reference to the Theory of Knowledge, Attitude, Belief, and Practice 
(KABP or KAP). According to this theory, appropriate health care knowledge is the foundation for developing positive and correct beliefs and attitudes and therefore for improving health-related behaviours. On the basis of this theory, the framework of the CS-TBKAPQ was divided into three sections: knowledge, attitudes, and practices towards TB.

\section{Phase 2: Item generation}

The original items of the CS-TBKAPQ were generated from the results of literature reviews and individual interviews. The literature reviews covered domestic and foreign studies on KAP towards TB and questionnaire development. The research team conducted ten interviews in total. The personal in-depth semi-structured interviews were conducted on issues such as TB health education, TB discovery and screening, and questionnaire item development. Each interview lasted 20 to $30 \mathrm{~min}$. The interviewees were one institute director, one division director and two other staff members of the TB Prevention Institute of Shaanxi Province, as well as two infectious disease administrators, two physicians and two radiologists from the university hospital.

\section{Phase 3: Item screening \\ Delphi technique}

Two rounds of consultations were conducted by experts in related fields via email. The experts were asked to rate all items using a five-point Likert scale, with five being the most important and one being the least important (including "neutral"). The mean and standard deviation of the score of each item were calculated. The variation coefficient and item selection rate were chosen as item screening indices. The item selection rate was calculated by the proportion of items given a rating of 4 or 5 by all experts. The screening standard was "the item whose variation coefficient $\geq 0.20$ or selection rate $<80 \%$ shall be deleted".

\section{Phase 4: Pre-testing}

To test the clarity and intelligibility of each item, the pre-final version of the CS-TBKAPQ was distributed to a sample of 40 college students.

\section{Measures}

The questionnaire was composed of four parts: demographic data, knowledge, attitudes, and practices towards TB. Each question of the knowledge section was rated in such a way that a score of one was given to correct responses and a score of zero was used for incorrect/don't know responses. The score of multiple-choice questions was cumulative. A Likert scale was used to quantify the results of the other two parts. A five-point Likert scale was utilized from 1 (completely disagree) to 5 (completely agree) with a neutral midpoint for each item of the attitudes section. A four-point Likert scale was utilized from 1 (completely disagree or never) to 4 (completely agree or always) for each item of the practices section. Questions closely related to individual subjective feelings such as "first response after suffering TB", "the reasons to refuse to participate in TB health education activity", and "the reasons to refuse timely treatment after TB infection" were scored zero. The flowchart of the study is shown in Fig. 1.

\section{Data analysis}

SPSS version 18.0 and Amos 17.0 were used for analysis. The questionnaires that were not filled out completely were regarded as invalid, and their data were discarded.

(1)Descriptive statistics were used to summarize the demographic data.

(2) Reliability of the CS-TBKAPQ was assessed by calculating Cronbach's $\alpha$ coefficient, the split-half reliability coefficient and the test-retest reliability coefficient. Split-half reliability was measured by numbering KAP items of the questionnaire and dividing them into two parts containing odd and even numbers. The simple correlation coefficient of the scores of the two parts was then calculated. The test-retest correlations were determined by calculating the interclass correlation coefficient (ICC) of the scores of the two surveys conducted among the same group of students in a twoweek interval. The statistically acceptable reliability coefficient should be $>0.70[15,16]$.

(3) Content validity was evaluated in the second round of expert consultation. The experts were asked to

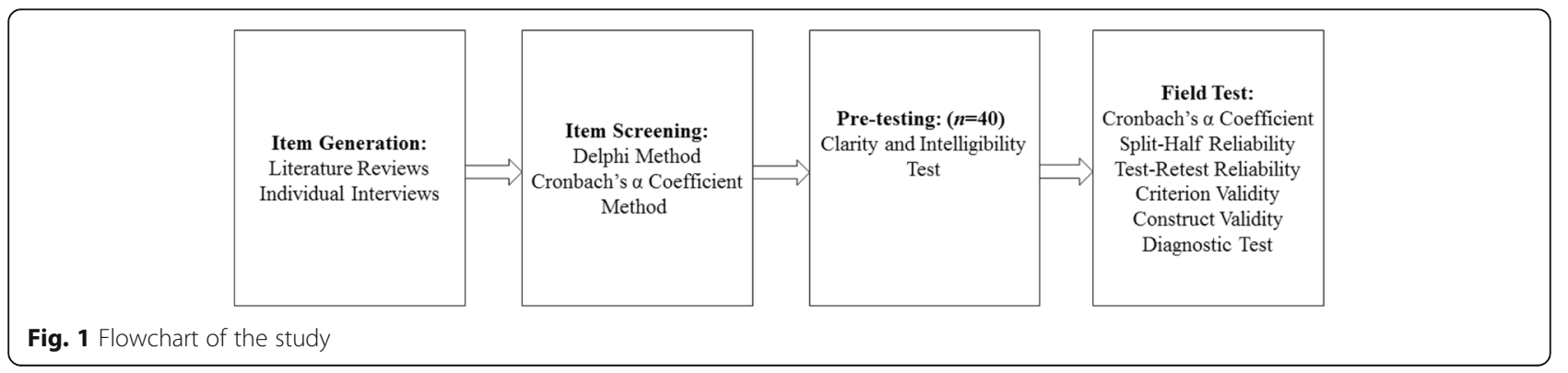


validate the relevance and feasibility of each item on a four-point Likert scale. The CVI was calculated by the proportion of items given a rating of 3 or 4 by all experts. The CVI should often be $>0.70[15,17]$.

(4) Construct validity of the CS-TBKAPQ was assessed by EFA. Factors were extracted by principal component factor analysis with a varimax orthogonal rotation method. Bartlett's test of Sphericity and a Kaiser-Meyer-Olkin (KMO) test must be conducted to confirm the suitability of data [18]. Bartlett's test of Sphericity with $p<0.05$ and a KMO value of 0.60 were suitable when running the EFA [15]. There are two useful techniques in factor extraction: the Kaiser's criterion for factors with an eigenvalue $>1$ and the Cattell's scree test. Cattell recommends in the scree test that all factors above the elbow, or break in the plot, should be retained [19]. Factor loadings greater than 0.40 were considered significant.

(5) Confirmatory factor analysis (CFA) was conducted to confirm the factorial structure of the CSTBKAPQ identified in the EFA. As the scores did not follow a normal distribution, the generalized least squares (GLS) method was adopted to conduct parameter estimation [19]. Model fit indices, such as NC (normed Chi-square $=x^{2} / d f$, $d f$ stands for 'degrees of freedom'), GFI (goodness of fit index), AGFI (adjusted goodness of fit index), RMSEA (root mean square error of approximation) and RMR (root mean square residual) were used for model goodness-of-fit assessment. The model fit is acceptable if NC $\left(x^{2}\right)$ $d f)<3(p>0.05)$, GFI $>0.90$, AGFI $>0.90$, RMSEA $<0.08$ and $\mathrm{RMR}<0.05$ [15].

(6) Criterion validity was assessed by testing the correlations between the scores of the overall CSTBKAPQ, the knowledge element, the attitudes element, the practices and the two other generic measures used in the public TB KAP survey: the CDC-TBKAPQ and the WHO-TBKAPQ. As the scores of the three questionnaires did not follow a normal distribution, the Spearman rank correlation coefficient was calculated.

(7)Diagnostic accuracy assessment included two aspects: First, a comparative analysis was conducted on the sensitivity and specificity of the CS-TBKAPQ and the CDC-TBKAPQ. The CDCTBKAPQ was a generic questionnaire and was a widely used tool in public KAP surveys in China. The theoretical assumption was that the specificity of the CS-TBKAPQ was higher than that of the CDC-TBKAPQ. Second, the diagnostic accuracy of the CS-TBKAPQ was evaluated using the calculated sensitivity, the specificity, the positive predictive value (PPV) and the negative predictive value (NPV).

\section{Reference standard selection}

In this research, the WHO-TBKAPQ was selected as the reference standard of the diagnostic test. The WHOTBKAPQ was developed by the WHO and can be considered the most widely accepted questionnaire among the existing tools in KAP assessment. Furthermore, the WHO-TBKAPQ has been used with modifications by some countries and has demonstrated good reliability, sensitivity and cultural acceptability. For instance, Daniel Tolossa applied the WHO-TBKAPQ to investigate community knowledge, attitudes, and practices towards TB in Ethiopia [4].

\section{Receiver operator characteristic (ROC) curve analysis}

The participants who filled in each of the three questionnaires, namely, the WHO-TBKAPQ, CDC-TBKAPQ and CS-TBKAPQ, were divided into two groups based on the median of their scores. The participants who scored above the median were recognized to have high KAP levels, and the participants who scored below the median were recognized as having low KAP levels. Using the score of the WHO-TBKAPQ as criteria, the ROC curves of the scores of the CDC-TBKAPQ and the CSTBKAPQ were drawn to determine the cut-off points of the two questionnaires.

\section{Calculation of diagnostic test index}

The sensitivity of the diagnostic test indicates the percentage of college students who were correctly classified by the test as having low-level KAP. The PPV is the percentage of college students with a positive test outcome who actually have low-level KAP.

\section{Results \\ Delphi technique}

The 12 experts were from the TB prevention, clinical treatment, health education and college TB management fields. Their average age was 49.83 years $(\mathrm{SD}=10.85)$, and the average length of service was 15.25 years $(\mathrm{SD}=7.97)$. The experts with titles indicating senior professional posts accounted for $75 \%$. Their academic backgrounds were closely related to the CS-TBKAPQ development. Following the first round, four items were deleted, as the selection rate was $<80 \%$ or the variation coefficient was $\geq 0.2$. The deleted items related to knowledge of TB infectivity, attitudes towards self-probability of TB infection, coepidemics of TB and HIV, and attitudes towards TB patients. Two items related to the purpose of the purified protein derivative (PPD) test and the vaccine to prevent TB were added in the first round. In the second round, the two newly added items were deleted due to the selection rate of $<80 \%$. The initial questionnaire with twentyfour KAP items was developed through two rounds of the Delphi technique (Table 1). 
Table 1 Results of the Delphi Technique

\begin{tabular}{lllllll}
\hline Round & $\begin{array}{l}\text { Original } \\
\text { items }\end{array}$ & $\begin{array}{l}\text { Items } \\
\text { unmodified }\end{array}$ & $\begin{array}{l}\text { Items } \\
\text { modified }\end{array}$ & $\begin{array}{l}\text { Items } \\
\text { deleted }\end{array}$ & $\begin{array}{l}\text { Added } \\
\text { items }\end{array}$ & Result \\
\hline 1 & 28 & 14 & 9 & 4 & 2 & 26 \\
2 & 26 & 24 & 0 & 2 & 0 & 24 \\
\hline
\end{tabular}

\section{Pre-testing}

Forty new students of Xian Jiaotong University participated in the pre-testing and completed the questionnaire within $13 \mathrm{~min}$. After revising the descriptions of some items according to the feedback, the pre-final questionnaire was determined. This questionnaire consisted of twenty-four KAP items.

\section{Sampling}

A total of 710 college students participated in the field test through simple random sampling, which was more than the minimum required number of participants. The participants filled out the CS-TBKAPQ, the CDC-TBKAPQ and the WHO-TBKAPQ at the same time. Because fifteen participants did not complete the CS-TBKAPQ, the sample size of the valid CS-TBKAPQ was 695. The 695 data sets were used to assess reliability by calculating Cronbach's $\alpha$ coefficient, the split-half reliability coefficient, and the test-retest reliability coefficient. The 695 data sets were also randomly divided into two groups. EFA was performed for the $\mathrm{N} 1$ dataset $(n=347)$, and CFA was performed for the $\mathrm{N} 2$ dataset $(n=348)$. Each participant was required to write in his/her student ID when filling out the questionnaire, and each questionnaire was given an ID from '001' to '710'. Sixty questionnaires were randomly selected based on the questionnaire ID by systematic sampling. The questionnaire IDs were then matched with the student IDs to identify the participants. The sixty selected students were recruited in the retest study two weeks later, and all of the participants completed the questionnaires.

In the criterion validity assessment and the diagnostic test, the research team compared the results of the CSTBKAPQ and the CDC-TBKAPQ using the WHOTBKAPQ as the reference standard. The participant's data were useful if all three questionnaires were completed. There were 69 participants who did not finish all three questionnaires. Thus, the sample size was 641 for the criterion validity assessment and the diagnostic test.

\section{Demographic characteristics}

The minimum, maximum, mean and standard deviation of the CS-TBKAPQ scores $(n=695)$ were $62,12,46.54$ and 8.57, respectively. We demonstrated the demographic characteristics of the samples of the EFA, CFA and diagnostic test in Table 2 . In the EFA $(\mathrm{N} 1=347)$ and CFA samples $(\mathrm{N} 2=348)$, differences in demographic
Table 2 Demographic Characteristics of Participants

\begin{tabular}{|c|c|c|c|c|c|}
\hline & $\begin{array}{l}\text { EFA } \\
(\mathrm{N} 1=347)\end{array}$ & $\begin{array}{l}\text { CFA } \\
(\mathrm{N} 2=348)\end{array}$ & $x^{2} / z$ & $p$ & $\begin{array}{l}\text { Diagnostic } \\
\text { test }(n=641)\end{array}$ \\
\hline Gender & & & 0.53 & 0.47 & \\
\hline Male & 152 & 162 & & & 297 \\
\hline Female & 195 & 186 & & & 344 \\
\hline Age $(M \pm Q)$ & $20 \pm 3$ & $20 \pm 3$ & -1.78 & 0.08 & $20 \pm 3$ \\
\hline Nationality & & & 0.04 & 0.85 & \\
\hline Han & 331 & 333 & & & 611 \\
\hline Minority & 16 & 15 & & & 30 \\
\hline Residence & & & 1.05 & 0.31 & \\
\hline Urban & 169 & 156 & & & 306 \\
\hline Rural & 178 & 192 & & & 335 \\
\hline Dormitory type & & & 2.04 & 0.56 & \\
\hline 4-person & 107 & 100 & & & 190 \\
\hline 6-person & 153 & 161 & & & 286 \\
\hline 8-person & 52 & 60 & & & 107 \\
\hline Other & 35 & 27 & & & 58 \\
\hline $\begin{array}{l}\text { Monthly living } \\
\text { expense }\end{array}$ & & & 2.48 & 0.65 & \\
\hline$<500$ yuan & 41 & 44 & & & 77 \\
\hline 500-1000 yuan & 140 & 143 & & & 255 \\
\hline $1001-1500$ yuan & 117 & 102 & & & 207 \\
\hline 1501-2000 yuan & 33 & 43 & & & 74 \\
\hline$>2000$ yuan & 16 & 16 & & & 28 \\
\hline $\begin{array}{l}\text { Father's education } \\
\text { background }\end{array}$ & & & 4.63 & 0.20 & \\
\hline Primary School & 20 & 28 & & & 44 \\
\hline Junior High School & 100 & 118 & & & 194 \\
\hline Senior High School & 139 & 118 & & & 241 \\
\hline Bachelor's Degree & 88 & 84 & & & 162 \\
\hline $\begin{array}{l}\text { Mother's education } \\
\text { background }\end{array}$ & & & 2.19 & 0.54 & \\
\hline Primary School & 52 & 57 & & & 103 \\
\hline Junior High School & 102 & 114 & & & 190 \\
\hline Senior High School & 109 & 107 & & & 201 \\
\hline Bachelor's Degree & 84 & 70 & & & 147 \\
\hline $\begin{array}{l}\text { Past learning } \\
\text { experience }\end{array}$ & & & 0.01 & 0.91 & \\
\hline Yes & 162 & 164 & & & 298 \\
\hline No & 185 & 184 & & & 343 \\
\hline Past contact & & & 0.00 & 0.99 & \\
\hline Yes & 60 & 60 & & & 111 \\
\hline No & 287 & 288 & & & 530 \\
\hline Total & 347 & 348 & & & 641 \\
\hline
\end{tabular}


characteristics such as gender, age, nationality, residence, health education history and contact history with TB patients had no statistical significance.

\section{Reliability \\ Cronbach's a coefficient}

The change analysis assesses the effect of deleting an item on the Cronbach's $\alpha$ coefficient. After deleting the three items "what do you think of the prevalence of TB in the past and present period", "what's your response to your knowledge that your classmate suffers TB" and "behaviour of preventing TB", the Cronbach's $\alpha$ coefficient showed values of $0.83,0.83$ and 0.85 , respectively, manifesting a relatively high increase compared with the overall value $(0.82)$. Therefore, the three items were deleted. The final questionnaire was then developed. This questionnaire consisted of 31 items, including ten demographic characteristic items and twenty-one KAP items, eighteen of which were scoring items.

The Cronbach's $\alpha$ coefficients were 0.86 for the total questionnaire, 0.42 for the knowledge element, 0.92 for the attitudes element, and 0.73 for the practices element. The split-half reliability coefficient was 0.78 . Test-retest reliability estimated from ICC was 0.91 (95\%CI: 0.781-0.995).

\section{Content validity}

The CVI was 0.89, which achieved Lynn's [20] criterion for content validity, indicating that the questionnaire can reflect the content of college students' KAP towards TB.

\section{Exploratory factor analysis}

The KMO value of Sample N1 $(n=347)$ was 0.91, and the result of Bartlett's test of Sphericity was $3299.08(p<0.001)$, which indicated that the data were suitable for factor analysis. The results of the EFA revealed four eigenvalues greater than 1.0. An inspection of Cattell's scree plot (Fig. 2) revealed a clear break after the fourth component. Therefore, four components were retained, which accounted for $62.52 \%$ of the variance. The factor loading with each item was above 0.4 without cross-loadings. According to the factor loading result and the item content, the first factor (F1) was named prevention attitude and behaviour, which involved nine items; the second factor (F2) was named active learning and treatment behaviour, which involved three items; the third factor (F3) was named disease knowledge, which involved four items; and the fourth factor (F4) was named treatment knowledge, which involved two items (Table 3).

\section{Confirmatory factor analysis}

The CFA model of the CS-TBKAPQ was composed of four factors and 18 items, including F1 (items A5, A4, A8, A7, A3, A9, P5, P7, and A2), F2 (items P1, P2, and P3), F3 (items K4, K2, K3, and K6), and F4 (items K5 and K7). The parameter estimation results of GLS showed that no negative error variables appeared in the model and that all parameter estimations reached a significant level. Additionally, the estimation results did not contradict the model identification rule. The four-factor model failed to achieve exact fit $\left(x^{2} / d f=1.82, p<0.001\right)$. An acceptable fit was indicated by GFI $=0.925$, AGFI $=$ 0.900 , RMSEA $=0.049$ and RMR $=0.068$ [15]. All of the standardized factor loadings were statistically significant and greater than 0.40 (except items K4, K5 and K6). The parameter estimates of the CFA are shown in Fig. 3.

\section{Criterion validity}

The CS-TBKAPQ showed significant positive correlation with the WHO-TBKAPQ and the CDC-TBKAPQ $(r=0.59$, 0.60 , respectively, $p<0.001)$. The knowledge items showed moderate correlation with the WHO-TBKAPQ and the CDC-TBKAPQ $(r=0.50,0.55$, respectively, $p<0.001)$. The attitudes items showed moderate correlation with the WHO-TBKAPQ and the CDC-TBKAPQ $(r=0.47$ and 0.46 , respectively, $p<0.001$ ). The practices items showed moderate correlation with the WHO-TBKAPQ and the CDC-TBKAPQ $(r=0.43$ and 0.40 , respectively, $p<0.001)$.

\section{Diagnostic test}

Figure 4 presented the ROC curve computed for the scores of the CS-TBKAPQ and its three parts using the WHO-TBKAPQ score as criteria. The areas under the ROC curve for the CDC-TBKAPQ and the CS-TBKAPQ were 0.80 (95\% CI: $0.767-0.836$ ) and 0.82 (95\% CI: 0.788-0.853), respectively. The best cut-off point of the CDC-TBKAPQ for screening purposes was 13.5, which resulted in a sensitivity of $71.70 \%$ and a specificity of $72.56 \%$. The best cut-off point of the CS-TBKAPQ was 47.5 , which resulted in a sensitivity of $73.63 \%$, a specificity of $80.51 \%$, a PPV of $83.23 \%$, and an NPV of $69.91 \%$, suggesting a good yield for discriminating between the students with low KAP levels from those with higher levels. In total, of the 641 college students surveyed, 322 (50.20\%) had low KAP levels, and 319 (49.80\%) had relatively high KAP levels. According to the ROC curve result, the best cut-off points for the knowledge, attitudes and practices elements of the CS-TBKAPQ were 5.5, 28.50 and 13.50, respectively. The analysis result is shown in Table 4.

\section{Discussion}

To our knowledge, research focusing on questionnaire development of college students' KAP towards TB is 


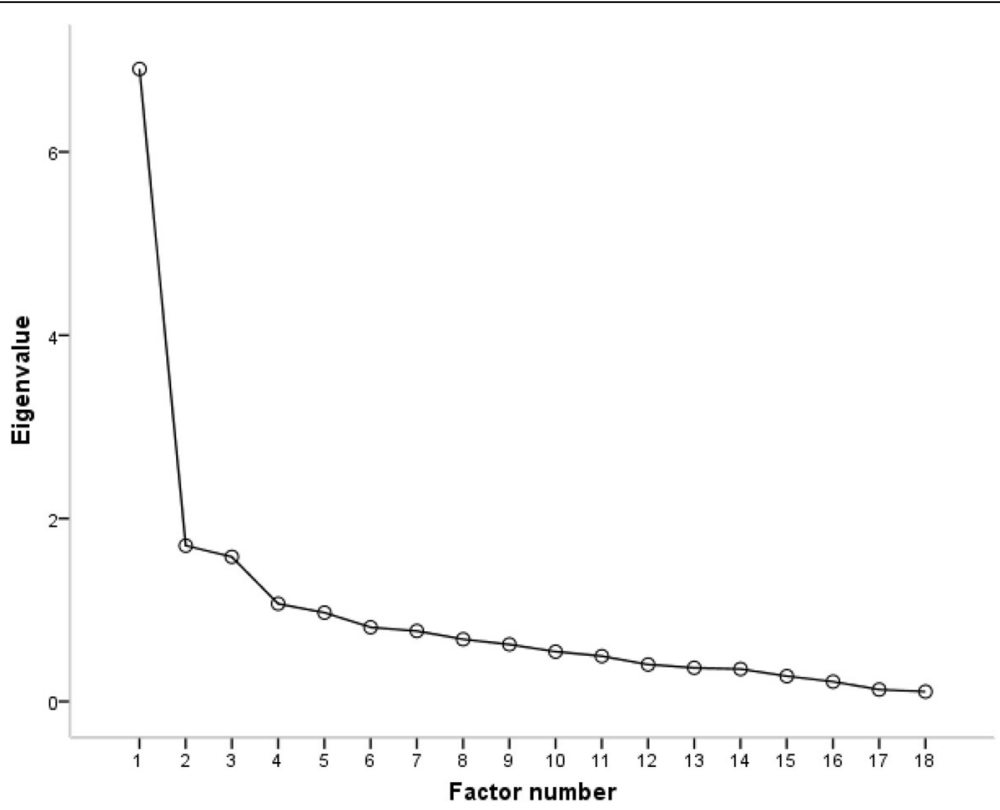

Fig. 2 Cattell's Scree Plot

Table 3 Factor Loading Results of the Exploratory Factor Analysis

\begin{tabular}{|c|c|c|c|c|c|}
\hline \multicolumn{2}{|c|}{ Item } & \multirow{2}{*}{$\frac{F 1}{0.896}$} & \multirow{2}{*}{$\frac{F 2}{0.142}$} & \multirow{2}{*}{$\frac{F 3}{0.104}$} & \multirow{2}{*}{$\frac{F 4}{-0.013}$} \\
\hline A5 & College students should participate in a TB health education activity held by the school. & & & & \\
\hline A4 & The school should hold a TB health education activity. & 0.884 & 0.083 & 0.108 & 0.006 \\
\hline A8 & $\begin{array}{l}\text { After discovering an epidemic outbreak of TB, students should coordinate the field investigation } \\
\text { of a disease control institution. }\end{array}$ & 0.882 & 0.072 & 0.183 & -0.004 \\
\hline A7 & College students should coordinate TB screening held by the school. & 0.866 & 0.132 & 0.152 & -0.028 \\
\hline A3 & College students should know relevant TB information. & 0.831 & 0.043 & 0.150 & 0.025 \\
\hline A9 & $\begin{array}{l}\text { What is your attitude if the doctor suggests "preventative treatment" when a PPD test is discovered } \\
\text { to be positive? }\end{array}$ & 0.817 & 0.164 & 0.088 & 0.062 \\
\hline P6 & You will actively accept a physical examination when your classmate suffers from TB. & 0.748 & 0.112 & 0.051 & 0.015 \\
\hline P5 & You remind your classmates to have a physical examination when you suffer from TB. & 0.666 & 0.305 & 0.089 & 0.000 \\
\hline A2 & College students with confirmed TB should tell a counsellor about the disease. & 0.557 & 0.150 & 0.131 & -0.071 \\
\hline P1 & Will you actively increase your TB knowledge? & 0.132 & 0.834 & 0.001 & 0.020 \\
\hline P2 & Will you actively tell your family members or friends the TB knowledge you have gained? & 0.230 & 0.803 & 0.119 & 0.001 \\
\hline P3 & You will see a doctor in a timely fashion when you discover suspicious TB symptoms. & 0.400 & 0.554 & 0.023 & 0.029 \\
\hline K3 & Which of the following symptoms is a sign of TB? & 0.121 & 0.045 & 0.778 & 0.084 \\
\hline K1 & What is the transmission route of TB? & 0.060 & 0.042 & 0.725 & 0.323 \\
\hline K2 & What is a TB-vulnerable student? & 0.233 & -0.027 & 0.680 & -0.035 \\
\hline K5 & Free TB treatment institution. & 0.096 & 0.106 & 0.463 & -0.271 \\
\hline K4 & Can TB be cured? & 0.185 & -0.138 & 0.066 & 0.804 \\
\hline K6 & Free TB examination and treatment policy & -0.190 & 0.301 & 0.040 & 0.547 \\
\hline \multicolumn{2}{|c|}{ Eigenvalue } & 6.902 & 1.704 & 1.581 & 1.068 \\
\hline \multicolumn{2}{|c|}{ Contribution rate (\%) } & 38.346 & 9.464 & 8.781 & 5.931 \\
\hline \multicolumn{2}{|c|}{ Cumulative contribution rate (\%) } & 38.346 & 47.810 & 56.591 & 62.523 \\
\hline
\end{tabular}




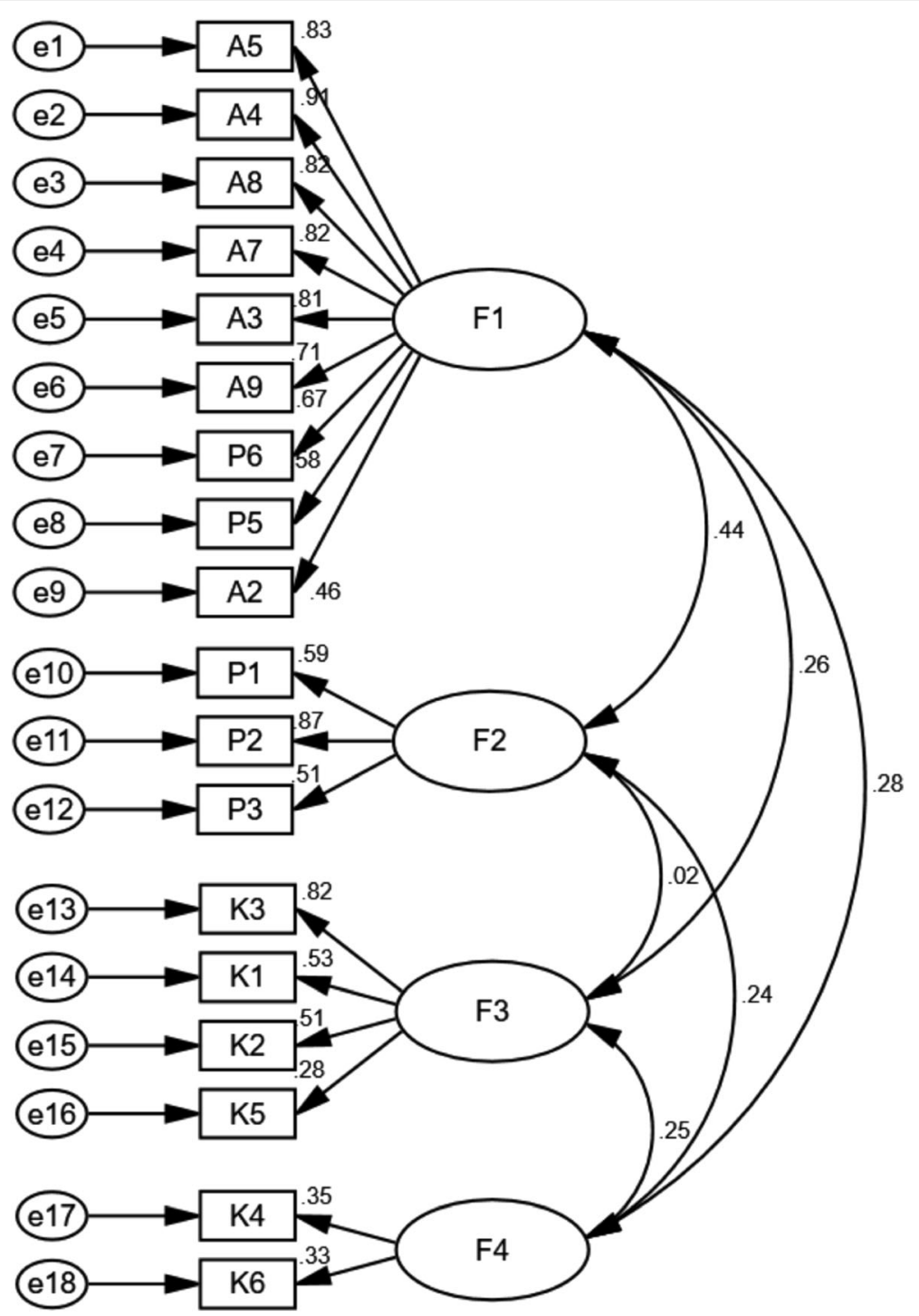

Fig. 3 Path Diagram of the Confirmatory Factor Analysis

limited. Additionally, few tools have been developed for this specific purpose following the scale development steps. In this study, we produced a 31-item CS-TBKAPQ and evaluated its reliability, validity and diagnostic accuracy. The CS-TBKAPQ is more consistent with real-world conditions than the WHO-TBKAPQ in assessing TB prevention and control among college students in China. The CS-TBKAPQ performs better than the CDC-TBKAPQ in diagnosing low-level KAP students.

Cronbach's $\alpha$ coefficient, the split-half reliability coefficient and the test-retest reliability coefficient were above 0.7 , showing acceptable internal consistency and reliability $[15,16,20]$. The construct validity analysis showed that the four factors extracted in EFA explained 62.52\% of the total variance, which was higher than the criterion of $50 \%$. All factor loadings were above 0.4 , revealing close relations between factors and items [19]. The fourfactor model of CFA failed to perfectly fit the collected data as demonstrated by the highly significant Chisquare test for exact fit; however, this test is known to be overly sensitive to sample size [16]. Approximate fit indices were proposed to overcome this difficulty. The RMR value of 0.068 was deemed acceptable, and the other model fit indices reached the ideal standard, therefore demonstrating highly acceptable model fit with the observed data. CFA and EFA verified that the CSTBKAPQ had reasonable construct validity.

The criterion validity analysis demonstrated that the CS-TBKAPQ had moderate correlations with the WHOTBKAPQ and the CDC-TBKAPQ [20]. Some items of the three questionnaires overlapped in topics, such as the core knowledge of TB, the attitudes towards health 


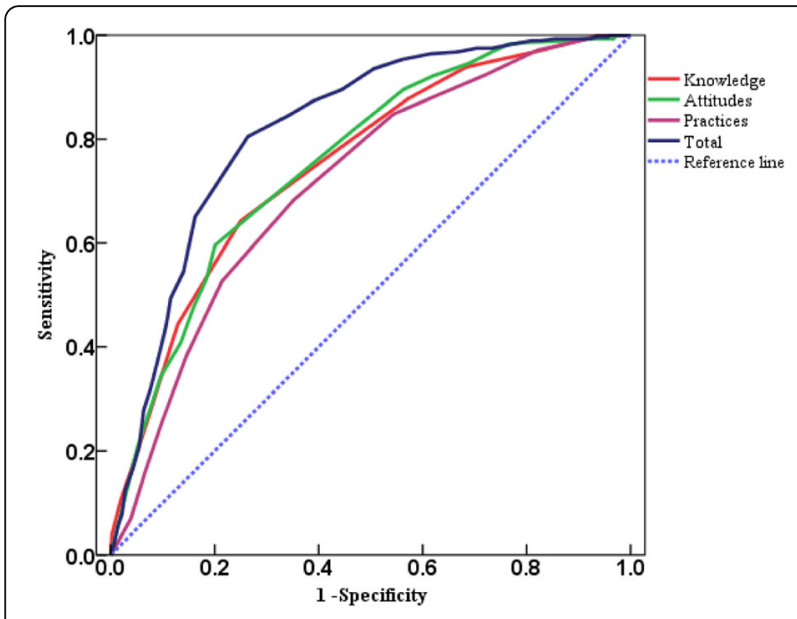

Fig. 4 Roc Curve of the CS-TBKAPQ

education, the practices of active learning and knowledge dissemination. Thus, several new items that reflected characteristics of college TB control were added in the CS-TBKAPQ. The newly added items included the knowledge item "ТВ susceptible population among students"; the attitudes items regarding informing the university when you suffer $\mathrm{TB}$, coordinate $\mathrm{TB}$ screening and a field investigation by the CDC in an epidemic outbreak; as well as the practices items "remind surrounding students to conduct physical examination, and seek help from doctors if your classmates suffer TB" and "timely treatment after discovering suspicious symptoms". These items embodied the differences between the CS-TBKAPQ and the two general questionnaires.

The diagnostic test showed that the specificity $(80.51 \%)$ of the CS-TBKAPQ was higher than that of the CDC-TBKAPQ (72.56\%), which verified the theoretical assumption that "the specificity of the questionnaire specially developed for college students shall be higher than the CDC-TBKAPQ developed for the public". The diagnostic test also proved the necessity of developing the CS-TBKAPQ. The sensitivity and specificity of the CSTBKAPQ were $73.63 \%$ and $80.51 \%$, respectively, suggesting that the CS-TBKAPQ is a valuable tool for identifying students with low KAP levels [21, 22]. We found that $50.20 \%$ of 641 college students had low KAP levels and that $49.80 \%$ of them had relatively high KAP levels, indicating a high proportion of students with low KAP levels and demonstrating a lack of sufficient knowledge, positive attitudes and sound practices regarding TB. This conclusion has good consistency with the findings by Faustine Nkulu [23] that "the proportions with good knowledge and positive attitudes of 16-24 years old students were $11.1 \%$ and $44.4 \%$, the proportions with good knowledge and positive attitudes of students having more than 12 years of education were $23.2 \%$ and $55.8 \%$. This finding was also consistent with Milos Smolovic's [9] statement that students not having sufficient knowledge about the cause and transmission mode of TB should be prioritized in TB health education.

The CS-TBKAPQ also indicated potential targeted interventions to improve KAP levels in its assessment of the cut-off points for knowledge, attitudes and practices. For instance, it is important for students with insufficient knowledge to participate in TB-related health education curricula [8], and those with poor attitudes should be guided through peer education to strengthen TB knowledge internalization [4]. In addition, students without sufficient practice should be encouraged to participate in $\mathrm{TB}$ prevention-themed activities and to improve their knowledge and attitudes towards health practices $[8,12]$.

TB prevention and control among college students has become an important public health issue in China. Evidence has shown that health education on KAP can help reduce the incidence and burden of TB. It can also help in early detection, isolation and treatment to prevent outbreaks. The study provides a simple, practical tool, the CS-TBKAPQ, to evaluate the KAP level among college students. This tool can be used in baseline data collection for targeted health education and intervention.

There are some limitations to this research. Only universities in Shaanxi Province were selected for the field test. The samples can be expanded to the other regions of China in further studies. In the knowledge section, Cronbach's $\alpha$ coefficient was 0.42 , which failed to meet the requirement of no less than 0.70 , which may be due

Table 4 Diagnostic Test Results of the CS-TBKAPQ and CDC-TBKAPQ

\begin{tabular}{|c|c|c|c|c|c|c|c|c|}
\hline & \multirow{2}{*}{$\begin{array}{l}\text { Sensitivity } \\
(\%)\end{array}$} & \multirow{2}{*}{$\begin{array}{l}\text { Specificity } \\
(\%)\end{array}$} & \multirow{2}{*}{$\begin{array}{l}\text { Diagnosis } \\
\text { result }\end{array}$} & \multicolumn{2}{|c|}{ Reference standard } & \multirow[t]{2}{*}{ Total } & \multirow{2}{*}{$\begin{array}{l}\text { PPV } \\
(\%)\end{array}$} & \multirow{2}{*}{$\begin{array}{l}\text { NPV } \\
(\%)\end{array}$} \\
\hline & & & & Low & High & & & \\
\hline \multirow[t]{3}{*}{ CS-TBKAPQ } & 73.63 & 80.51 & Low & 268 & 54 & 322 & 83.23 & 69.91 \\
\hline & & & High & 96 & 223 & 319 & & \\
\hline & & & Total & 364 & 277 & 641 & & \\
\hline \multirow[t]{3}{*}{ CDC-TBKAPQ } & 71.70 & 72.56 & Low & 261 & 76 & 337 & 77.45 & 66.12 \\
\hline & & & High & 103 & 201 & 304 & & \\
\hline & & & Total & 364 & 277 & 641 & & \\
\hline
\end{tabular}


to the knowledge items covering TB symptoms, transmission and treatment policies. The overall Cronbach's $\alpha$ coefficient was 0.86 . Therefore, the reliability of the internal consistency of the questionnaire was considered adequate.

\section{Conclusions}

The CS-TBKAPQ is a theory-based tool that was developed following the scale development steps. The study demonstrated that the CS-TBKAPQ has good internal consistency, test-retest reliability, content validity, construct validity, and criterion validity. As a specific TB KAP measure for college students, the CS-TBKAPQ is more sensitive and specific than the generic measure based on the diagnostic test results. This questionnaire can be used to investigate the TB KAP level of college students in China and to provide baseline data for health education or the evaluation of health education [24]. In addition, it can also be used to analyse the association between KAP and socio-economic factors [5].

\section{Abbreviations}

AlID: Cronbach's alpha coefficient if item deleted; CFA: Confirmatory factor analysis; CVl: Content validity index; EFA: Exploratory factor analysis; GLS: Generalized Least Squares method; ICC: Interclass correlation coefficient; KAP: Knowledge, attitudes, and practices; NPV: Negative predictive value; PPV: Positive predictive value; ROC: Receiver operator characteristic curve; TB: Tuberculosis

\section{Acknowledgements}

This study was supported by the National Science Foundation of China (Award number: 71774131). We also sincerely thank the Shaanxi Provincial Institute for Tuberculosis Control and Prevention for their fully support. We would also like to thank the efforts of the research team and the cooperation of the participated college students.

\section{Funding}

This research was funded by the National Science Foundation of China (Award number: 71373203).

\section{Availability of data and materials}

All data generated or analysed during this study are included in this published article. The datasets used and/or analysed during the current study available from the corresponding author on reasonable request.

\section{Authors' contributions}

HLJ, SRZ and YLL designed the study. HLJ and YD drafted the manuscript. THZ and WPL contributed to data collection. YHF, YL and XXM contributed to individual interviews, data collection and data analysis. YD and RQZ participated in results interpretation and revision of the paper. All authors read and approved the final manuscript.

\section{Ethics approval and consent to participate}

The study was approved by Xi'an Jiaotong University Ethics Committee. All respondents voluntarily participating in this research were informed of the investigation topic and form. The written informed consent was obtained from all the participants before enrollment in the study.

\section{Consent for publication}

Not applicable.

\section{Competing interests}

The authors declare that they have no competing interests.

\section{Publisher's Note}

Springer Nature remains neutral with regard to jurisdictional claims in published maps and institutional affiliations.

\section{Author details}

${ }^{1}$ Health Science Center, Xi'an Jiaotong University, Xi'an city, China.

${ }^{2}$ Department of Pharmacy, Xijing Hospital, Fourth Military Medical University, Xi'an city, China. ${ }^{3}$ Shaanxi Provincial Institute for Tuberculosis Control and Prevention, Xi'an city, China. ${ }^{4}$ Shaanxi University of Chinese Medicine, Xi'an city, China.

Received: 16 January 2017 Accepted: 29 November 2017

Published online: 12 December 2017

\section{References}

1. World Health Organization. Global Tuberculosis Report. Geneva: WHO report; 2015.

2. Zhang S, Ruan W, Li Y, Wang X, Wang X. Experiences of the parents caring for their children during a tuberculosis outbreak in high school: a qualitative study. BMC Public Health. 2014;14:132.

3. Li X, Zhang S, Yan H, Zhang T, Zhang J. Barriers to tuberculosis control and prevention in undergraduates in Xi'an, China: a qualitative study. J PUBLIC HEALTH POL. 2010;31(3):355-68.

4. Tolossa D, Medhin G, Legesse M. Community knowledge, attitude, and practices towards tuberculosis in Shinile town, Somali regional state, eastern Ethiopia: a cross-sectional study. BMC Public Health. 2014;14:804.

5. Rana M, Sayem A, Karim R, Islam N, Islam R, Zaman TK, Hossain G. Assessment of knowledge regarding tuberculosis among non-medical university students in Bangladesh: a cross-sectional study. BMC Public Health. 2015;15(1):716

6. Chen W, Xia Y, Li X, Zhou L, Li C, Wan K, Cheng S. A tuberculosis outbreak among senior high school students in China in 2011. J INT MED RES. 2012; 40(5):1830-9.

7. Orrett FA, Shurland SM. Knowledge and awareness of tuberculosis among pre-university students in Trinidad. J Community Health. 2001;26(6):479-85.

8. Naidoo S, Taylor M. Association between south African high-school learners' knowledge about tuberculosis and their intention to seek healthcare. Glob Health Action. 2013;6:21699.

9. Smolovic M, Pesut D, Bulajic M, Simic M. Knowledge and attitudes towards tuberculosis in non medical students University of Belgrade. Pneumologia. 2012;61(2):88-91.

10. Benkert R, Resnick B, Brackley M, Simpson T, Fair B, Esch T, Field K Tuberculosis education for nurse practitioner students: where we are and where we need to go. J Nurs Educ. 2009:48(5):255-65.

11. World Health Organization. Advocacy, communication and social mobilization for TB control: a guide to developing knowledge, attitude and practice surveys. Geneva: World Health Organization; 2008.

12. Moges B, Amare B, Yismaw G, Workineh M, Alemu S, Mekonnen D, Diro E, Tesema B, Kassu A. Prevalence of tuberculosis and treatment outcome among university students in Northwest Ethiopia: a retrospective study. BMC Public Health. 2015;15(1):15.

13. Rattray J, Jones MC. Essential elements of questionnaire design and development. J Clin Nurs. 2007;16(2):234-43.

14. Lin C, Cheng C, Kuo S, Chou F. Development of a Chinese short form of the prenatal self-evaluation questionnaire. J Clin Nurs. 2009:18(5):659-66.

15. Chen $X, H u Y, Z$ hu D, Li J, Zhou L. Chinese version of the aging perceptions questionnaire (C-APQ): assessment of reliability and validity. Aging Ment Health. 2016;20(6):567-74.

16. Leung AY, Lou WW, Cheung MK, Chan SS, Chi I. Development and validation of Chinese health literacy scale for diabetes. J Clin Nurs. 2013;22(15-16): 2090-9.

17. Wang H, Chao YC, Tsai J, Chung M, Yu Y, Hang L, Lee S. Development and preliminary validation of a questionnaire on regular exercise beliefs among patients with chronic obstructive pulmonary disease. J Clin Nurs. 2014;23(78):1133-43.

18. Oroviogoicoechea C, Watson R, Beortegui E, Remirez S. Nurses' perception of the use of computerised information systems in practice: questionnaire development. J Clin Nurs. 2010;19(1-2):240-8.

19. Li WH, Chung JO, Chui MM, Chan PS. Factorial structure of the Chinese version of the 12-item general health questionnaire in adolescents. J Clin Nurs. 2009;18(23):3253-61. 
20. Zhang X, Wang A. Development of a psychosocial adaptation questionnaire for Chinese patients with visual impairments. J Clin Nurs. 2011;20(19-20): 2822-9.

21. Yin $X$, Tu X, Tong $Y$, Yang $R$, Wang $Y$. Development and validation of a tuberculosis medication adherence scale. PLoS One. 2012;

22. van der Zwaan GL, van Dijk SEM, Adriaanse MC, van Marwijk HWJ, van Tulder MW, Pols AD, Bosmans JE. Diagnostic accuracy of the patient health Questionnaire-9 for assessment of depression in type II diabetes mellitus and/or coronary heart disease in primary care. J AFFECT DISORDERS. 2016; 190:68-74.

23. Nkulu FK, Hurtig AK, Ahlm C, Krantz I. Screening migrants for tuberculosis a missed opportunity for improving knowledge and attitudes in high-risk groups: a cross-sectional study of Swedish-language students in Umea, Sweden. BMC Public Health. 2010;10:349.

24. Rakotosamimanana S, Mandrosovololona V, Rakotonirina J, Ramamonjisoa J, Ranjalahy JR, Randremanana RV, Rakotomanana F. Spatial analysis of pulmonary tuberculosis in Antananarivo Madagascar: tuberculosis-related knowledge, attitude and practice. PLoS One. 2014;9:e11047111.

Submit your next manuscript to BioMed Central and we will help you at every step:

- We accept pre-submission inquiries

- Our selector tool helps you to find the most relevant journal

- We provide round the clock customer support

- Convenient online submission

- Thorough peer review

- Inclusion in PubMed and all major indexing services

- Maximum visibility for your research

Submit your manuscript at www.biomedcentral.com/submit
Biomed Central 